\title{
Alterações patológicas e identificação da Escherichia coli como agente causal da celulite aviária em frangos de corte inspecionados em um matadouro de São Paulo
}

\section{Pathological alterations and identification of Escherichia coli as causal agent of avian celulitis in inspectioneted broilers chickens from a slaughterhouse of São Paulo}

\author{
Cláudia Leal Andrade, ${ }^{*}$ Gustavo Bernardo Ferreira, ${ }^{*}$ Robson Maia Franco, ${ }^{\star \star}$ Elmiro Rosendo do Nascimento, ${ }^{\star \star *}$ \\ Rogerio Tortelly****
}

\begin{abstract}
Resumo
Neste estudo foi analisada a descrição macroscópica e microscópica das lesões típicas de celulite em frangos de corte e sua associação com a presença da bactéria Escherichia coli. Foram coletados 30 fragmentos de pele com suspeita macroscópica de celulite e 30 controle. A partir destas amostras, foram realizadas análises bacteriológicas e histopatológicas. Das 30 amostras suspeitas de celulite, todas foram confirmadas na histopatologia, enquanto nas amostras controle, somente uma apresentou características histológicas da doença. Das amostras com confirmação histopatológica, 23 (76,6\%) foram positivas para a presença de E. coli. As principais alterações macroscópicas encontradas foram o espessamento e irregularidade da pele, alterações na coloração e placas amarelas destacáveis no subcutâneo. Microscopicamente, havia placas fibrinosas ricas em restos celulares no subcutâneo, envoltas por um infiltrado inflamatório de histiócitos ou por infiltrado de heterófilos e células gigantes multinucleadas e fibrose. $\mathrm{Na}$ análise bacteriológica, dentre as duas metodologias utilizadas, o método direto e o de enriquecimento, o direto foi o que obteve maior número de isolamento de $E$. coli.
\end{abstract}

Palavras-chave: frangos de corte, celulite, Escherichia coli, histopatologia

\begin{abstract}
In this study were described the lesions of cellulitis in broilers chickens and then compared with their Escherichia coli isolates. A total of 30 birds were selected based on the presence of skin lesions similar to those of cellulitis and 30 were control samples. Skin with gross findings was collected for bacterial and pathological analyses, as well the control ones. All the 30 suspicious samples matched the histopathological features, while among the control, only one of them had characteristics of cellulitis. Among the samples with histopathological findings, $23(76,6 \%)$ were positive for $E$. coli. The main gross changes were skin thickness and irregularity, color alteration and yellow detached plaques in the subcutaneous. Microscopically there were fibrinous plaques of cellular debris in the subcutaneous tissue envolved by an inflammatory infiltration with histiocytes or by an infiltration and multinucleated giant cells and fibrosis. On bacteriological analysis, between the two methods used, the straight and the enriched one, the direct method had more isolations of $E$. coli.
\end{abstract}

Keywords: broilers, cellulitis, Escherichia coli, histopathology.

\section{Introdução}

A indústria avícola tem importância significativa na economia mundial, e no Brasil, movimenta bilhões de dólares por ano. Em 2005, a avicultura brasileira manteve-se na posição de terceiro maior produtor de carne de frango, com uma produção recorde de 9,3 milhões de toneladas de carne, 9,5\% maior que o volume de 2004, quando produziu 8,5 milhões de toneladas (ABEF, 2006). Com todo esse crescimento econômico e evolução na produção, a preocupação com os aspectos sanitários também aumentou e, com isso, o aprimoramento tecnológico deve estar associado à evolução nas pesquisas relacionadas com a sanidade das aves.

* Programa de Pós-graduação em Medicina Veterinária (Mestrado) - Higiene Veterinária e Processamento Tecnológico de Produtos de Origem Animal - Faculdade de Veterinária, Universidade Federal Fluminense.

** Departamento de Tecnologia dos Alimentos - Faculdade de Veterinária, Universidade Federal Fluminense. E-mail: robsonmf@vm.uff.br.

*** Departamento de Saúde Coletiva Veterinária e Saúde Pública - Faculdade de Veterinária, Universidade Federal Fluminense. E-mail: elmiro@vm.uff.br.

**** Departamento de Patologia e Clínica Veterinária - Faculdade de Veterinária, Universidade Federal Fluminense. E-mail: rtortel@microlink.com.br. Autores para correspondência: Claudia Leal Andrade. E-mail: leal.andrade@gmail.com e Gustavo Bernardo Ferreira. E-mail: ferreiragb@ig.com.br. 
Muitas enfermidades causam grandes prejuízos à indústria avícola e de acordo com critério de julgamento do médico veterinário, essas doenças acarretam condenações das carcaças e/ou vísceras na linha de inspeção, durante o abate das aves. De acordo com a Normativa $n^{\circ} 210$ de 10/11/98 do Ministério da Agricultura Pecuária e Abastecimento (Brasil, 1998), qualquer órgão ou partes da carcaça que estiverem afetados por um processo inflamatório, como a celulite, deverão ser retirados. Havendo evidência de caráter sistêmico da patologia, a carcaça e as vísceras deverão ser condenadas na sua totalidade.

Apesar do ótimo desempenho nos últimos anos, a avicultura apresenta problemas com relação à sanidade das aves. Em função do tipo de criação, em escala industrial, dos frangos de corte, as enfermidades cutâneas vêm-se tornando cada vez mais freqüentes, com crescentes prejuízos econômicos. Estas enfermidades são causas de condenação parcial ou total das carcaças nos matadouros, com redução no valor do produto final, despesas com mão-de-obra adicional e equipamentos, redução na velocidade de processamento das carcaças e gastos com limpeza e desinfecção das instalações.

A celulite é definida como um processo inflamatório que pode resultar na presença de um exsudato purulento agudo no tecido subcutâneo, sendo tipicamente observada na região da coxa e baixo abdome (Elfadil et al., 1996).

Além de sua importância econômica, a celulite é preocupante em termos de saúde coletiva, tendo em vista que inúmeros microrganismos estão envolvidos neste processo, principalmente a Escherichia coli, que pode ser isolada na maioria das lesões (Messier et al., 1993; Onderka et al., 1997), associada ou não a outros microrganismos (Peighambari et al., 1995).

Acredita-se que a celulite resulte de uma quebra na integridade da pele, como um ferimento traumático ou outra abrasão cutânea, permitindo que as bactérias entrem e colonizem o tecido subcutâneo (Norton, 1997).

Apesar da grande importância econômica e de saúde coletiva dessa enfermidade, existem raros trabalhos das alterações patológicas observadas associadas à presença de E. coli. Portanto, o presente estudo objetivou caracterizar as alterações macro e microscópicas da celulite em frangos, indicar suas principais localizações em frangos de corte na linha de abate, comprovar o papel da E. coli na gênese do processo inflamatório e comparar as técnicas de isolamento.

\section{Material e métodos}

Durante a inspeção post mortem em um matadouro de aves no estado de São Paulo, foram colhidos fragmentos de pele de frangos de corte, com aspecto irregular, espessado e com alteração de coloração. O período de colheita foi de seis dias, dividido em duas etapas de três dias.

Em cada dia, foram colhidas amostras de pele de cinco carcaças apresentando alterações macroscópicas sugestivas de celulite e amostras de pele de cinco carcaças sem alterações macroscópicas, sendo cada uma dessas subseqüentes às aves suspeitas, constituindo o grupo controle. No total, foram estudadas amostras de pele de 30 carcaças com suspeita de celulite e de 30 carcaças controle. Como as lesões não podem ser visualizadas na carcaça intacta, utilizaram-se essas alterações na pele dos frangos como indicadores de celulite após a depenagem das aves.

Os frangos tinham idade aproximada de 45 dias. As lesões foram mensuradas e descritas macroscopicamente. De cada uma, foi retirado um fragmento para exame histopatológico e outro para o exame bacteriológico. Dos casos controle foi retirado um fragmento de local e tamanho equivalentes ao retirado dos frangos suspeitos. As amostras de pele destinadas à histopatologia foram identificadas e fixadas em formol a $10 \%$ e remetidas ao Serviço de Anatomia Patológica Veterinária Professor Jefferson Andrade dos Santos na Faculdade de Veterinária da Universidade Federal Fluminense para processamento pelas técnicas habituais de inclusão em parafina e coloração pelo método hematoxilina-eosina. Para o exame bacteriológico, os fragmentos foram colocados, assepticamente, em envelopes plásticos previamente esterilizados em autoclave a $121^{\circ} \mathrm{C}$ por 15 minutos e selados por seladora industrial. Os envelopes foram identificados, colocados em um recipiente isotérmico contendo gelo e remetidos ao Laboratório de Controle Microbiológico de Produtos de Origem Animal do Departamento de Tecnologia de Alimentos da Faculdade de Veterinária da Universidade Federal Fluminense, onde foi realizada a análise bacteriológica. A metodologia utilizada foi uma adaptação àquela descrita por Quinn et al. (1994).

De cada fragmento foram retiradas três amostras com swabs estéreis, que foram inoculadas em meio caldo soja triptona (Oxoid no CM129), em placa com o meio ágar sangue, composto de meio ágar columbia (Merck no 10455) com 5\% de sangue desfibrinado de carneiro, e em placa com o meio ágar MacConkey lactose (Merck no 5465). Após incubação a $37^{\circ} \mathrm{C}$ por 24 horas, realizou-se a leitura das placas, de onde se retirou uma colônia típica de Escherichia coli, de cada uma delas. Do caldo soja triptona, semeou-se o material em meio ágar sangue e ágar MacConkey. De cada placa, semeou-se uma colônia em meio inclinado de Triple Sugar Iron - TSI (Merck no 3915), que foi incubado a $37^{\circ} \mathrm{C}$ por 24 horas. Neste meio, a Escherichia coli utiliza a glicose, tornando o meio amarelo e produzindo gás. Se confirmada a presença de $E$. coli, esta era retirada com auxílio de uma alça de platina flambada e era realizada a semeadura em caldo soja triptona, sendo incubada a $37^{\circ} \mathrm{C} / 24$ horas para a seriação bioquímica.

A partir das culturas puras em caldo soja triptona, confeccionaram-se esfregaços em lâminas, corados pelo método de Gram e visualizados ao microscópio. Confirmando-se a presença de bastonetes Gram-negativos, eram realizadas as provas bioquímicas para confirmação do microrganismo.

Inicialmente, realizou-se a prova do indol e mobilidade em meio SIM (Merck no 5470) e a prova do citrato em meio de Simmons (Merck $n^{\circ}$ 2501). O teste de citrato foi realizado com a semeadura do inóculo da cultura em ágar citrato de Simmons a $35^{\circ} \mathrm{C}$ por 24 horas e então foi observado se houve ou não crescimento bacteriano. As culturas indol positivas e citrato negativas foram repicadas em meio denominado MILi, que identifica a família Enterobacteriaceae, através dos testes de motilidade, produção de indol e lisina descarboxilase, e em meio chamado EPM, que permite a realização simultânea dos testes de produção de gás a partir da glicose, produção de sulfeto de hidrogênio $\left(\mathrm{H}_{2} \mathrm{~S}\right)$, urease e triptofano desaminase.

As análises estatísticas foram realizadas no programa Statistix versão 3.1. Utilizou-se o teste de qui-quadrado de McNemar para simetria nas comparações entre a utilização do método 
direto e com enriquecimento não-seletivo; e o teste quiquadrado de independência para as comparações entre os períodos de coleta e entre os meios de cultura semeados. Em todas as análises, adotou-se erro tipo 1 (á) de $5 \%(0,05)$ (Thrusfield, 2003).

\section{Resultados}

As principais alterações macroscópicas da celulite nos frangos de corte estudados foram o espessamento da pele, alterações na coloração e irregularidade da superfície cutânea. Todas estas características foram tidas como indicadoras de celulite e pré-requisitos para a escolha das aves suspeitas. As lesões variavam de tamanho entre cinco e dez centímetros, sempre unilateralmente. Dentre as 30 amostras suspeitas coletadas, 29 estavam presentes na região de abdome e coxa (Figura 1) e uma no peito. A coloração da pele variou entre amarelo-pálido e amarelo-avermelhado. Ao corte, notou-se a presença de fluido gelatinoso e placas amarelas destacáveis no subcutâneo (Figura 2), e em alguns casos, a musculatura adjacente estava visivelmente comprometida. Nas amostras controle, não foram observadas alterações macroscópicas.

Com a leitura das lâminas, foram encontradas alterações microscópicas que indicam o diagnóstico positivo para celulite. Dentre os 30 casos suspeitos macroscopicamente, todos apresentavam características histopatológicas da doença: ora por placas fibrinosas ricas em restos celulares no subcutâneo, envoltas por um infiltrado inflamatório de histiócitos (Figura 3), ora por infiltrado de heterófilos e células gigantes multinucleadas e fibrose, além de espessamento da derme, com tecido de granulação. O processo freqüentemente ocasionava necrose da derme, esteatonecrose e infiltrava a musculatura regional (Figura 4), destruindo-a. Muitas vezes, havia presença de células inflamatórias na região perivascular.

Utilizando a metodologia direta, sem prévia semeadura em meio indicador não-seletivo, os isolamentos de $E$. coli em casos suspeitos somaram 48 e em casos controle somaram 24. Após o enriquecimento da cultura, antes da semeadura em ágar sangue e ágar MacConkey, foram isoladas 41 culturas de E. coli de casos suspeitos e 34 de casos controle. Do total de isolamentos, 44 culturas de E. coli oriundas de casos suspeitos foram isoladas utilizando a semeadura em placa de ágar sangue, e 45 de ágar MacConkey. Dos casos controle, macroscópica (direita). foram isoladas 31 colônias de E. coli provenientes de ágar sangue e 27 de placa de ágar MacConkey.

De forma geral, das 30 amostras com celulite comprovadas através do exame histopatológico, 23 foram positivas na identificação de E. coli, e das amostras controle, 18 confirmaram a presença da bactéria.

Comparando os tratamentos utilizados na bacteriologia, na Tabela 1 houve diferença estatística significativa $(p<0,05)$ entre 0 número de isolamentos de $E$. coli nos métodos direto e com prévio enriquecimento não-seletivo nas aves com celulite e sem celulite, sendo a maior freqüência para os casos de isolamento direto, segundo o teste de qui-quadrado de McNemar.

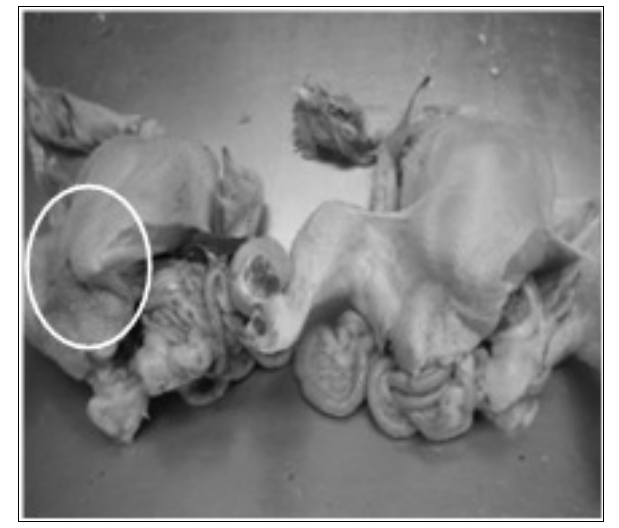

Figura 1: Carcaça de frango de corte com lesão de celulite na região de abdome e coxa (esquerda) e uma carcaça controle sem alteração

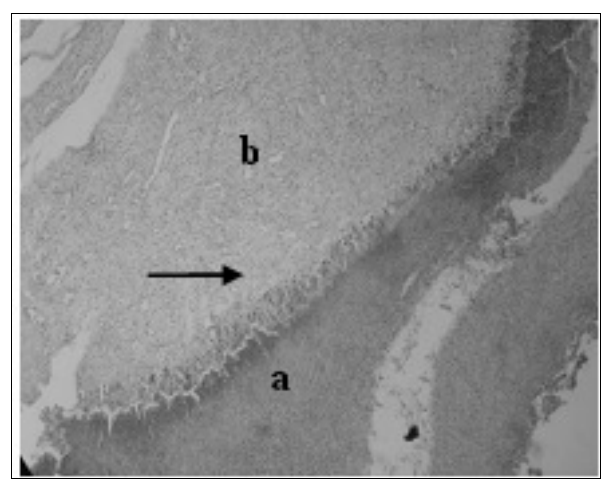

Figura 3: Frango. Celulite. Placa fibrino-caseosa (a) envolta por uma barreira de histiócitos (seta) circundado pelo tecido fibroso (b). H. E. Obj. 4X.

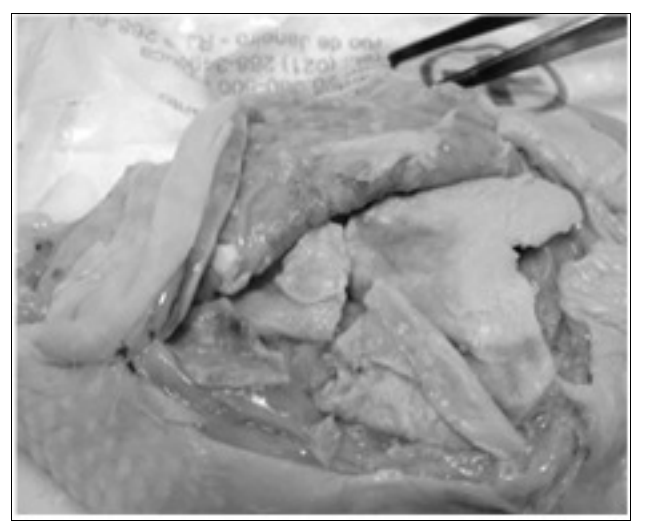

Figura 2: Frango. Celulite. Presença de placas amarelas, firmes e destacáveis no subcutâneo.

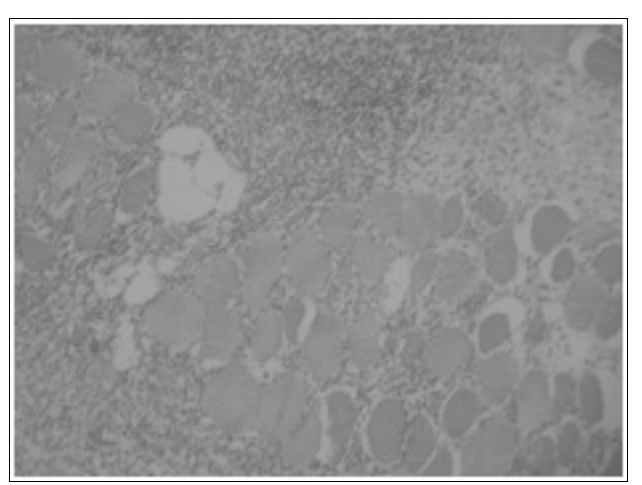

Figura 4: Frango. Celulite. Infiltrado inflamatório na musculatura regional. H. E. Obj.10X.

Tabela 1: Comparação entre o número de casos suspeitos e de casos controle nas metodologias direta e com enriquecimento, na análise bacteriológica das amostras

\begin{tabular}{ccc}
\hline Análise Bacteriológica & $\begin{array}{c}\text { Número de } \\
\text { casos suspeitos }\end{array}$ & $\begin{array}{c}\text { Número de } \\
\text { casos controle }\end{array}$ \\
\hline Metodologia direta & 48 & 24 \\
Metodologia com enriquecimento & 41 & 34 \\
\hline Total & 89 & 58 \\
\hline
\end{tabular}


$\mathrm{Na}$ Tabela 2, comparando o número de isolamentos de E. coli nos meios ágar sangue e ágar MacConkey, não houve diferença estatística significativa $(p>0,05)$ entre os meios de cultura, segundo o teste de McNemar. Ou seja, a escolha do meio de cultura utilizado não interferiu no isolamento da $E$. coli.

Tabela 2: Comparação entre o número de casos suspeitos e de casos controle nos meios de cultura ágar sangue e ágar MacConkey, utilizados no isolamento da E.coli

\begin{tabular}{ccc}
\hline Meios de Cultura & $\begin{array}{c}\text { Número de casos } \\
\text { suspeitos }\end{array}$ & $\begin{array}{c}\text { Número de casos } \\
\text { controle }\end{array}$ \\
\hline ágar sangue & 44 & 31 \\
ágar MacConkey & 45 & 27 \\
\hline Total & 89 & 58 \\
\hline
\end{tabular}

\section{Discussão}

Neste estudo, a maioria das lesões estava presente na região ventral e na coxa, assim como ocorreu no trabalho de Peighambari et al. (1995) e de Gomis et al. (2001), que notaram que as lesões macroscópicas de celulite eram predominantes na área abdominal, com lesões similares na coxa e na região caudal. Em poucas aves, a celulite apresentava, macroscopicamente, somente fluido amarelado. Tal estágio de desenvolvimento também foi observado neste estudo, sendo considerado como fase inicial de desenvolvimento da doença, havendo posteriormente, uma organização tecidual, que tende a formar as placas típicas da celulite.

Fallavena et al. (2000) afirmaram que, embora sejam consideradas características, as alterações macroscópicas não são específicas e, deste modo, o exame realizado no matadouro não permitiria a classificação das enfermidades cutâneas. Por isto, a histopatologia é tão importante para sua diferenciação, pois $61 \%$ das lesões apresentaram uma característica típica da celulite. Entretanto, de acordo com os achados no presente estudo, a inspeção visual realizada no momento do abate pode ser de grande importância em estágios avançados da doença, pois há desenvolvimento das placas fibrinosas sob a pele.

Fallavena (2001) também relatou que a utilização de exames histológicos indicou que o aumento da espessura da pele é um achado freqüente em muitas doenças cutâneas, assim como as alterações macroscópicas, como a coloração, nódulos escuros nos folículos das penas e formação de crostas. Porém, o próprio autor assume que a localização das lesões é decisiva na classificação da doença, pois a celulite aviária é mais comum no abdome, ao contrário de outras doenças cutâneas. Tal afirmativa foi comprovada neste estudo, pois quase a totalidade das lesões estava presente na região mais incriminada.

Neste trabalho, as lesões microscópicas foram características e inferiram o correto diagnóstico da doença, dando subsídios para que a equipe da inspeção possa realizar o correto julgamento da carcaça. Segundo Onderka et al. (1997), a aparência da celulite parece realmente facilitar o correto reconhecimento da lesão pelos inspetores na planta de processamento. Os mesmos autores, assim como observado neste estudo, encontraram a presença de granulomas e placas fibrino-caseosas, e em algumas aves, células inflamatórias invadiram o músculo subcutâneo com proeminência de capilares congestos. Kumor et al. (1998) relatam que os microrganismos são encontrados além dos limites macroscópicos, logo, o correto julgamento da lesão deve ser realizado valorizando-se não só a estética da lesão, como também a preocupação sanitária envolvendo a questão. A partir disto, presume-se que há uma maior preocupação sanitária com relação à maneira mais segura de se identificar a enfermidade, e assim, minimizar os riscos envolvidos. O envolvimento bacteriano foi confirmado neste estudo, pois mais de $70 \%$ das amostras com alterações macroscópicas evidenciaram a $E$. coli.

O alto número de isolamentos do presente trabalho $(76,6 \%)$ também foi evidenciado em outros estudos: Gomis et al. (1997) isolaram $97,5 \%$ de E. coli e Gomis et al. (2001) isolaram $100 \%$. No estudo de Onderka et al. (1997), E. coli estava presente em $83 \%$ das lesões. Isto demonstra que esta bactéria está intimamente incriminada na patogenia da doença, sendo relacionada como o principal agente causal da doença.

Tendo em vista o relato apresentado no presente estudo, conclui-se que o infiltrado rico em heterófilos caracteriza a fase inicial da enfermidade, devendo ser classificada como celulite úmida, enquanto que a placa fibrinosa caracteriza celulite seca. Neste trabalho, verificou-se que a $E$. coli foi 0 agente etiológico principal da celulite em frangos de corte, pois estava presente em $76,6 \%$ das aves com comprovação histopatológica da doença.

Além disso, afirma-se que as alterações macroscópicas associadas à localização típica das lesões na carcaça podem indicar a presença da celulite em frangos de corte, sendo comprovadas posteriormente pela histopatologia.

\section{Agradecimento}

Ao Conselho Nacional de Desenvolvimento Científico e Tecnológico - CNPq, pelo apoio financeiro.

\section{Referências}

ABEF - Associação Brasileira dos Produtores e Exportadores de Frangos. Disponível em: <http://www.abef.com.br>. Acesso em: 17 nov. 2006.

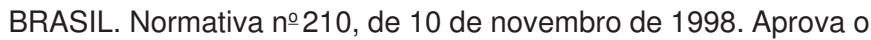
Regulamento Técnico da Inspeção Tecnológica e Higiênico-Sanitária de Carne de Aves. Diário Oficial da República Federativa do Brasil, Brasília, DF, 1998.
ELFADIL, A. A.; VAILLANCOURT, J. P.; MEEK, A. H. Farm management risk factors associated with cellulitis in broiler chickens in Southern Ontario. Avian Diseases, v. 40, p. 699-706, 1996.

FALLAVENA, L. C. B. Lesões Cutâneas em Frangos de Corte: Causas, Diagnóstico e Controle. In: CONFERÊNCIAAPINCO 2001 DE CIÊNCIAE TECNOLOGIA. 2001. Anais... Apinco, 2001. p. 205-216.

FALLAVENA, L. C. B; MORAES, H. L. S.; SALLE, C. T. P.; SILVA, A. B.; VARGAS, R. S.; NASCIMENTO, V. P.; CANAL, C. W. Diagnosis of skin 
lesions in condemned or downgraded broiler carcasses - a microscopic and macroscopic study. Avian Pathology, v. 29, p. 557-562, 2000.

GOMIS, S. M.; GOODHOPE, R.; KUMOR, L.; CADDY, N.; RIDDELL, C.; POTTER, A. A.;ALLAN, B. J. Isolation of Escherichia colifrom cellulitis and other lesions of the same bird in broilers at slaughter. Can Vet. Journal, v. 38, p. 159-162, 1997.

GOMIS, S. M.;RIDDELL, C.; POTTER,A. A.;ALLAN, B. J. Phenotypic and genotypic characterization of virulence factors of Escherichia coli isolated from broiler chickens with simultaneous occurrence of cellulitis and other colibacillosis lesions. The Canadian Journal of Veterinary Research, v. 65, p. 1-6, 2001.

KUMOR, L. W.; OLKOWSKI, A. A.; GOMIS, S. M.;ALLAN, B. J. Cellulitis in broilers chickens: epidemiological trends, meat hygiene, and possible human health implications. Avian Diseases, v. 42, p. 285-291, 1998.

MESSIER, S.; QUESSY, S.; ROBINSON, Y.; DEVRIESE, L. A.; HOMMEZ, J.; FAIRBROTHER, J. M. Focal Dermatitis and Cellulitis in Broilers
Chickens: Bacteriological and Pathological Findings. Avian Diseases, v. 37, p. 839-844, 1993.

NORTON, R. A. Avian Cellulitis. World's Poultry Science Journal, v. 53, n. 4, p. 337-349, 1997.

ONDERKA, D. K.; HANSON, J. A.; MCMILLAN, K. R.; ALLAN, B. Escherichia coli Associated Cellulitis in Broilers: Correlation with Systemic Infection and Microscopic Visceral Lesions, and Evaluation for Skin Trimming, Avian Diseases, v. 41, p. 935-940, 1997. PEIGHAMBARI, S. M.; VAILLANCOURT, J. P.;WILSON, R. A.; GYLES, C. L. Characteristics of Escherichia coli isolates from avian cellulitis. Avian Diseases, v. 39, p. 116-124, 1995.

QUINN, P.J.; CARTER, M.E.; MARKEY, B.; CARTER, G.R. Clinical Veterinary Microbiology. Mosby, London, 1994.648 p.

THRUSFIELD, M. Veterinary Epidemiology, 2. ed. Oxford: Blackwell Science, 2003. $483 p$ 